\title{
Gabapentin adjunctive to risperidone or olanzapine in partially responsive schizophrenia: an open-label pilot study
}

This article was published in the following Dove Press journal:

Neuropsychiatric Disease and Treatment

28 October 2010

Number of times this article has been viewed

\section{Adel Gabriel \\ Departments of Psychiatry and Community Health Sciences, University of Calgary, Alberta, Canada}

Correspondence: Adel Gabriel 2000 Pegasus Road NE, Calgary AB, T2E 8K7, Canada

Tel + I 4032919122

Fax + I 4037172899

Email gabriel@ucalgary.ca
Background: There is a great need in the treatment of schizophrenia for a drug, or drug combinations, to improve clinical response with fewer serious side effects. The objective of this study was to explore the therapeutic effects and tolerability of the anticonvulsant gabapentin as an adjunctive in the treatment of patients with partially responsive schizophrenia.

Methods: Ten consenting patients with a confirmed Diagnostic and Statistical Manual of Mental Disorders, 4th Edition, Text Revision diagnosis of schizophrenia were identified. All patients failed at least one 12-week treatment trial with risperidone or olanzapine. Gabapentin was added to ongoing antipsychotic treatment with olanzapine or risperidone for eight weeks. The primary outcome measure was the Positive and Negative Syndrome Scale (PANSS). Other scales included the Calgary Depression Scale (CDSS) and the Abnormal Involuntary Movement Scale (AIMS). Repeated-measures multivariate analysis of variance was utilized to examine changes in outcome measures over time with adjunctive treatment with gabapentin.

Results: There was a significant drop in the PANSS and CDSS scores at endpoint (week 8). There were no significant differences between the two treatment groups with regard to changes in all outcome measures or in AIMS score. The adjunctive treatments were well tolerated and side effects were transient.

Conclusion: Gabapentin could be used successfully as an adjunct to novel antipsychotics in partially responsive schizophrenia. However, large controlled studies are needed to examine the effectiveness of gabapentin in psychotic disorders.

Keywords: schizophrenia, refractory, adjunctive treatment, gabapentin, risperidone, olanzapine

\section{Introduction}

Treatment-resistant or refractory schizophrenia is a difficult to define condition of largely unknown prevalence. ${ }^{1}$ The most commonly accepted definition of treatmentresistant schizophrenia denotes patients with schizophrenia who, despite at least two adequate trials of classical neuroleptic drugs, have persistent moderate to severe positive, disorganized, or negative symptoms, together with poor social and work function over a prolonged period of time. This definition reflects the viewpoint of people with this illness, their family members, and mental health care providers. Approximately $30 \%$ (range $10 \%-45 \%$ ) of schizophrenic patients meet these criteria. ${ }^{2}$ Clozapine has been the standard treatment in this condition and is recognized unequivocally as being the most effective for refractory schizophrenia, even when stringently defined. ${ }^{1,3}$ In one large study $(\mathrm{FIN}-11, \mathrm{n}=66,881)$ it was found that long-term treatment with antipsychotic drugs is associated with lower mortality compared with no antipsychotic use, 
and that the lowest risk was for clozapine compared with other antipsychotics. ${ }^{4,5}$ However, the results from an earlier large follow-up study ( $n=1415$ ) failed to support the hypothesis that clozapine treatment is associated with significantly fewer deaths due to suicide, ${ }^{6}$ and in a recent critical appraisal, others identified a number of methodologic and conceptual issues with these claims, which make the interpretation of these findings problematic. ${ }^{7}$

Despite the fact that clozapine is uniquely effective in refractory schizophrenia, it is associated with high attrition rates, and those who discontinue treatment are more likely to have suffered significantly from poor outcomes. ${ }^{8}$ Furthermore, a substantial minority fail to benefit from clozapine. ${ }^{9}$ Clozapine has also been associated with bothersome side effects, some of which are serious, eg, agranulocytopenia, so needs regular full blood count monitoring, which makes its administration a cumbersome process for both patient and clinicians. ${ }^{10,11}$

It has been demonstrated in a number of studies that gamma-aminobutyric acid (GABA)-ergic medications may have a potential role in the treatment of schizophrenia. For example, laboratory evidence has generally supported the ability of GABA to reduce dopaminergic activity, and has suggested that GABA may be effective in combating hypofrontality by acting on the mesoprefrontocortical tracts in patients resistant to treatment with antipsychotic drugs. ${ }^{12,13}$ As a result, it has been claimed by some investigators that it might be possible to decrease negative symptoms and cognitive impairment in people with schizophrenia by treatment with glutamatergic drugs. ${ }^{13}$

Gabapentin is a novel anticonvulsant that is structurally related to GABA. It was synthesized as a structural analog of GABA, which is a well-known inhibitory neurotransmitter in the brain, with the hope that it would penetrate into the brain and have a GABA-mimetic effect. ${ }^{14}$ The mechanism of action of gabapentin is not yet fully understood, and there is no convincing evidence to suggest that it interacts with $\mathrm{GABA}_{\mathrm{A}}$ or $\mathrm{GABA}_{\mathrm{B}}$ receptors. Some investigators have proposed that gabapentin acts as an agonist at a subunit of $\mathrm{GABA}_{\mathrm{B}}$ receptors, although the evidence for this is conflicting. ${ }^{15,16}$ However, its role in the brain may be indirectly related to glutamate. Also, gabapentin has not been identified as a GABA reuptake inhibitor, and it is not converted to a GABA agonist. ${ }^{15,17}$ Gabapentin is a ligand of the $\alpha 2$ voltage-activated calcium channel subunits that are overexpressed in sensory neurons after nerve injury, which is the proposed mechanism of action of its analgesic effects. ${ }^{18}$
Gabapentin is not metabolized in humans, does not bind to plasma proteins, and is eliminated by renal excretion. Compared with other antiepileptic mood stabilizers, eg, carbamazepine and valproate, gabapentin has milder side effects, is well tolerated, is relatively safe in overdose, and is safe in combination with other antiepileptics. ${ }^{19}$ The most commonly encountered side effects include somnolence, dizziness, unsteadiness, nausea, and fatigue. ${ }^{20}$

From reviewing the literature, there is one case report of a patient with resistant schizophrenia who was treated with gabapentin and antipsychotic therapy in an open-label case study. In this case report, the authors reported that their patient's aggressive behavior stabilized after the administration of gabapentin. However, the patient's aggression resumed after cessation of gabapentin and restabilized following the drug's reintroduction. ${ }^{21}$ This was supported by others who found that adjunctive gabapentin was associated with a reduction in agitation in chronically hospitalized schizophrenic patients. $^{22}$ There has also been an open-label trial $(n=25)$ in which gabapentin was effective in the treatment of inpatients with bipolar disorder and schizoaffective disorders. The authors reported that $76 \%$ had a positive response, as measured by changes in Clinical Global Impression and Brief Psychiatric Rating Scale scores, and that the mean dose was $1440 \mathrm{mg} /$ day. ${ }^{23,24}$ Gabapentin was found to be effective in antipsychotic-induced akathisia that is unresponsive to conventional therapy, ${ }^{25}$ in the treatment of tardive dyskinesia, in antipsychotic-induced blepharospasm, in involuntary oromandibular movements, ${ }^{26}$ and in prophylaxis of clozapineinduced seizures. ${ }^{27}$

The author is not aware of any published controlled or open studies to date that have examined the efficacy and tolerability of gabapentin as an adjunctive to novel antipsychotics in the treatment of partially responsive schizophrenia. The objective of this pilot open-label study was to examine the therapeutic outcomes of adding gabapentin to existing prescribed antipsychotics in patients with the diagnosis of chronic partially responsive schizophrenia.

\section{Methods \\ Study design}

This was an eight-week open study of add-on use of gabapentin in subjects with chronic schizophrenia, who showed only a partial response to 12 weeks of treatment with olanzapine or risperidone. All patients provided informed consent. This study was approved by the University of Calgary Conjoint Scientific and Ethics Board. 


\section{Participants}

Patients recruited for this study were consenting males and females, aged 18-65 years, from an inpatient psychiatry unit of a teaching hospital. All patients had a Diagnostic and Statistical Manual of Mental Disorders, 4th Edition, Text Revision diagnosis of paranoid schizophrenia, confirmed by the Mini-International Neuropsychiatric Interview. ${ }^{28}$ All patients had shown a partial response to risperidone or olanzapine treatment for 12 weeks prior to adding gabapentin. Partial response was evidenced by $<20 \%$ reduction in the total Positive and Negative Syndrome Scale (PANSS) score, ${ }^{29}$ and all patients had a total PANSS score $\geq 80$ at baseline prior to adding gabapentin. All patients were treated as inpatients and remained adherent to the gabapentin adjunctive treatment for at least eight weeks. Patients with suicidal thoughts, mental retardation, head injury or organic brain disease, renal or hepatic impairment, and/or excessive use of alcohol or illicit drugs during the six weeks prior to consideration for the trial were excluded.

\section{Drug administration}

Gabapentin was added to the existing risperidone or olanzapine regimen and was titrated from $100 \mathrm{mg}$ three times a day with daily increments of $300 \mathrm{mg}$ a day as tolerated to a maximum of $1800 \mathrm{mg}$ a day. No patient received other concomitant antipsychotics during the eight weeks of adjunctive treatment with gabapentin. Zopiclone $7.5 \mathrm{mg}$ was utilized occasionally for sleep difficulties, and lorazepam 1-2 mg was utilized for severe agitation.

\section{Outcome measures}

Subjects underwent standardized ratings at baseline (before the addition of gabapentin) and at weeks 4 and 8 after addition of gabapentin. Outcome measures included changes in PANSS score ${ }^{29}$ (the primary efficacy measure), Calgary Depression Scale (CDSS), ${ }^{30}$ the Abnormal Involuntary Movement Scale (AIMS), ${ }^{31}$ and reported side effects.

\section{Data analysis}

Descriptive statistics were used to summarize demographic variables, duration of the illness, number of previous admissions for acute psychotic episodes, and types of previously failed novel antipsychotics. To examine changes in PANSS positive scores and CDSS scores over time in both the olanzapine and risperidone patients, we employed a repeatedmeasures multivariate analysis of variance (MANOVA). The dependent variables were the total PANSS scores and the CDSS scores. The two independent variables were time (three levels, ie, at baseline and at weeks 4 and 8) and treatment group (risperidone and olanzapine). The paired $t$-test was used to examine changes in AIMS scores, by pairing scores at baseline before adding gabapentin and those at week 8 , and one-way analysis of variance was used to examine differences in extrapyramidal symptom (EPS) scores between the risperidone and olanzapine treatment groups. The paired $t$-test was used to examine changes in AIMS at baseline and at week 8 of adjunctive treatment in each group.

\section{Results}

Table 1 summarizes the demographic variables, history of past hospitalizations for acute psychotic episodes, and details

Table I Demographics of subjects

\begin{tabular}{|c|c|c|c|c|}
\hline & \multicolumn{2}{|c|}{ Risperidone $(n=5)$} & \multicolumn{2}{|c|}{ Olanzapine $(n=5)$} \\
\hline & Mean (SD) & Minimum-Maximum & Mean (SD) & Minimum-Maximum \\
\hline Age (years) & $37.2(8.17)$ & $28-49$ & $40(9.3)$ & $27-52$ \\
\hline $\operatorname{Sex}(M / F)$ & $4 / 5$ & $80 \%$ & $5 / 0$ & $100 \%$ \\
\hline Duration of illness (years) & $10(6.14)$ & $5-20$ & $16.6(8.8)$ & $8-30$ \\
\hline Number of acute hospital treatments & $2.2(0.84)$ & $1-3$ & $3.2(1.4)$ & $\mathrm{I}-8$ \\
\hline Novel dose at baseline (mg)* & \multicolumn{2}{|c|}{$4.6(0.9)$ and dose range $4-6$} & \multicolumn{2}{|c|}{$20(0)$ and dose range $20-20$} \\
\hline Gabapentin dose (mg) & $1200(367)$ & $900-1800$ & $1080(402)$ & $900-1800$ \\
\hline $\begin{array}{l}\text { History of partial response to other } \\
\text { antipsychotic trials }\end{array}$ & \multicolumn{2}{|l|}{ Patients (n) } & \multicolumn{2}{|l|}{ Patients (n) } \\
\hline Previous novel antipsychotics alone & 1 & & I & \\
\hline Traditional oral antipsychotics & 3 & & 2 & \\
\hline $\begin{array}{l}\text { Depot IM injections (eg, haldol } \\
\text { decanoate or fluphenazine decanoate) }\end{array}$ & 2 & & 2 & \\
\hline
\end{tabular}

Note: *Prior to adding gabapentin adjunctive treatment.

Abbreviations: IM, intramuscular; SD, standard deviation. 
of partial response to previous treatments with antipsychotics. Ten patients (100\%) completed the eight-week trial of adjunctive treatment with gabapentin, and all patients were rated as moderately to severely ill before adjunctive treatment with gabapentin was initiated. Table 2 summarizes the results from the repeated-measures one-way analysis of variance for the total PANSS and CDSS outcome measures over time in all patients and in each novel treatment group. There were no significant differences between the risperidone and olanzapine treatment groups in any of the outcome measures. On the primary efficacy measure, there was a significant decrease in total PANSS scores for both olanzapine and risperidone patients $(P<0.001)$. At endpoint (week 8 of adjunctive treatment) there were four patients $(80 \%)$ in the risperidone group and two patients $(40 \%)$ in the olanzapine group who achieved a response with $>50 \%$ reduction in total PANSS score. Table 3 summarizes the calculated percentage of reduction in the PANSS scores in the two treatment groups.

The percentage of PANSS reduction was calculated by the following formula to take into account the value of 30 meaning "no symptoms" on the 1-7 scoring system of PANSS:

$\underline{\text { (PANSS baseline }- \text { PANSS at } 8 \text { weeks }) \times 100}$

PANSS at 8 weeks -30

A response rate based on percentage PANSS reduction, ie, a cutoff of at least $50 \%$ reduction, has been recommended recently to be used at least for acutely ill patients. ${ }^{32}$

\section{Tolerance to adjunctive treatment}

The adjunctive treatments were well tolerated in both risperidone and olanzapine patients. There was significant changes (df 9; $P<0.4$ ) at week 8 in AIMS scores (Table 2). The most commonly encountered extrapyramidal symptoms included parkinsonian tremors, hypokinesia, and rigidity. However, these symptoms appeared to improve in severity over time with adjunctive gabapentin treatment. At week 8 , there were no significant changes in AIMS score in either of the groups, nor any significant difference between the two treatment groups. All other side effects were mild and transient. These included sedation, drowsiness, dizziness, and headaches. At baseline (prior to adding gabapentin), two patients in each of the treatment groups reported parkinsonian symptoms, including tremors and rigidity, which seemed to improve in severity by week 8 of adjunctive treatment. All patients elected to continue on adjunctive treatment at the end of the trial. Table 4 outlines the reported side effects and AIMS score profile.

\section{Discussion}

In the present open pilot study, there was significant improvement in positive, general psychopathology and depressive symptoms in schizophrenic patients treated with gabapentin adjunctive to the atypical antipsychotics risperidone and olanzapine.

Despite being configurationally similar to GABA (known to be an inhibitory transmitter in the brain), gabapentin does not bind to GABA receptors. In contrast with earlier studies that failed to demonstrate that gabapentin can affect the neuronal content of GABA, more recent evidence suggests that gabapentin may increase GABA synthesis and decrease glutamatergic excitability by depressing astrocytic activity

Table 2 Changes in PANSS and CDSS ${ }^{a}$ over eight weeks employing repeated-measures multivariate analysis of variance

\begin{tabular}{|c|c|c|c|c|c|}
\hline \multirow[t]{2}{*}{ Measure } & \multirow[t]{2}{*}{ Groups } & \multirow[t]{2}{*}{ Time } & \multirow[t]{2}{*}{ Mean (SD) } & \multicolumn{2}{|l|}{$95 \% \mathrm{Cl}$} \\
\hline & & & & Lower limit & Upper limit \\
\hline \multirow[t]{3}{*}{ PANSS } & All patients & Baseline & $104(19.2)$ & 89.8 & II8.I \\
\hline & & 4 weeks & $90(13.4)$ & 80.5 & 99.7 \\
\hline & & 8 weeks & 78 (10.6) & 70.6 & 85.8 \\
\hline \multirow[t]{6}{*}{ PANSS } & Risperidone & Baseline & $108(16.9)$ & 87.0 & 129 \\
\hline & & 4 weeks & $90(12.3)$ & 75.8 & 105.0 \\
\hline & & 8 weeks & $78(6.3)$ & 66.4 & 89.6 \\
\hline & Olanzapine & Baseline & 101 (22.5) & 80.1 & 121.1 \\
\hline & & 4 weeks & $90(15.8)$ & 75.2 & 104.4 \\
\hline & & 8 weeks & $78(14.6)$ & 66.8 & 90.0 \\
\hline \multirow[t]{6}{*}{ CDSS } & Risperidone & Baseline & $13(2.0)$ & 8.4 & 18.0 \\
\hline & & 4 weeks & $7(2.7)$ & 4.7 & 10.1 \\
\hline & & 8 weeks & $3(2.5)$ & 0.4 & 5.6 \\
\hline & Olanzapine & Baseline & $16(6.3)$ & 11.4 & 21.0 \\
\hline & & 4 weeks & $10(2.4)$ & 7.3 & 12.7 \\
\hline & & 8 weeks & $5(2.5)$ & 1.1 & 7.21 \\
\hline
\end{tabular}

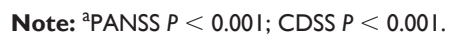

Abbreviations: $\mathrm{Cl}$, confidence interval; SD, standard deviation; PANSS, positive and negative syndrome scale; CDSS, calgary depression scale. 
Table 3 The percentage of PANSS reduction in the two treatment groups

\begin{tabular}{|c|c|c|c|c|c|c|}
\hline $\begin{array}{l}\text { Response ratel } \\
\text { treatment groups }\end{array}$ & $\begin{array}{l}\text { Patients } \\
\text { (n) }\end{array}$ & $\begin{array}{l}0 \%-25 \% \\
\text { PANSS } \\
\text { reduction } \\
\mathrm{n}(\%)\end{array}$ & $\begin{array}{l}25 \%-49 \% \\
\text { PANSS } \\
\text { reduction } \\
\text { n (\%) }\end{array}$ & $\begin{array}{l}50 \%-74 \% \\
\text { PANSS } \\
\text { reduction } \\
\mathrm{n}(\%)\end{array}$ & $\begin{array}{l}75 \%-100 \% \\
\text { PANSS } \\
\text { reduction } \\
n(\%)\end{array}$ & $\begin{array}{l}\text { Response rate } \\
\text { with }>\mathbf{5 0} \% \\
\text { PANSS reduction } \\
\mathrm{n}(\%)\end{array}$ \\
\hline Risperidone group & 5 & I (20) & 0 & $3(60)$ & I (20) & $4(80)$ \\
\hline Olanzapine group & 5 & 0 & $3(60)$ & $2(40)$ & 0 & $2(40)$ \\
\hline
\end{tabular}

Abbreviation: PANSS, positive and negative syndrome scale.

and suppressing glial calcium signaling and glutamate release. ${ }^{20,33}$ Although the present findings need further critical examination, they suggest that gabapentin functions as a GABA-ergic drug. Also, these findings would support the GABA hypothesis of schizophrenia, which suggests that there is insufficient GABA inhibition of dopaminergic neurotransmission in patients with schizophrenia. ${ }^{34-36}$

Antiepileptic drugs are commonly prescribed for major nonepileptic psychiatric disorders, including schizophrenia and bipolar disorders. ${ }^{37-40}$ There is some evidence that antiepileptic drugs, including carbamazepine, valproate, and lamotrigine, may change symptoms of schizophrenia by their action on GABA-ergic neurotransmission, or via antiglutamatergic mechanisms, by modifying the excitability of neurons through effects on voltage-gated sodium and calcium channels, or by promoting inhibition mediated by GABA receptors. Also, there is emerging evidence to suggest that antiepileptic drugs have effects on signaling pathways that regulate neuronal plasticity and survival. ${ }^{15,39,41}$ For example, the traditional antiepileptic carbamazepine was identified as a useful adjunct to antipsychotics in the treatment of resistant schizophrenia, with particular effects on reduction of violent and aggressive behavior, in improving the associated affective disturbances. ${ }^{42}$ The new antiepileptics (eg, gabapentin, oxcarbazepine, topiramate, vigabatrin)

Table 4 Reported side effects and AIMS score profile

\begin{tabular}{lll}
\hline Reported side effects & $\begin{array}{l}\text { Risperidone } \\
(\mathbf{n}=\mathbf{5})\end{array}$ & $\begin{array}{l}\text { Olanzapine } \\
(\mathbf{n}=\mathbf{5})\end{array}$ \\
\cline { 2 - 3 } & $\mathbf{n}(\%)$ & $\mathbf{n}(\%)$ \\
\hline Drowsiness & $2(40)$ & $3(60)$ \\
Dizziness & $2(40)$ & $2(40)$ \\
Headaches & $\mathrm{I}(20)$ & 0 \\
EPS profile at baseline & & \\
Parkinsonian bradykinesia & $\mathrm{I}(20)$ & $\mathrm{I}(20)$ \\
Tremors & $2(40)$ & $\mathrm{I}(20)$ \\
Rigidity & $\mathrm{I}(20)$ & $\mathrm{I}(20)$ \\
AIMS scores ( $\mathrm{n}=5$; df 4) & $\mathrm{M}(\mathrm{SD}), \mathrm{t}<P$ & $\mathrm{M}(\mathrm{SD}), \mathrm{t}<P$ \\
Baseline & $2.4(2.5)$ & $\mathrm{I} .6(2.3)$ \\
Week 8 & $2(2.0), \mathrm{I} .60 .2$ & $\mathrm{I} .2(\mathrm{I} .7), \mathrm{I} .60 .2$ \\
\hline
\end{tabular}

Abbreviations: AIMS, abnormal involuntary movement scale; EPS, extrapyramidal symptom; SD, standard deviation. have promise as potential adjuncts to antipsychotics for treating resistant symptoms of schizophrenia. ${ }^{41}$ For example, in a recent meta-analysis, it was concluded that lamotrigine augmentation may be an effective treatment for patients with clozapine-resistant schizophrenia, and that a substantial proportion of the most severely ill patients appeared to obtain clinically meaningful benefit from this combination treatment. ${ }^{43,44}$ However, results from two multicenter, randomized, double-blind studies did not support the use of lamotrigine as an adjunct to atypical antipsychotics in patients with refractory psychosis. ${ }^{45}$

Knowledge of the sites and mode of action of antiepileptic drugs, such as gabapentin in the synapse, is important in order for us to improve our understanding of their broad spectrum of clinical efficacy and to develop effective drugs for the treatment of both epilepsy and other neurologic and psychiatric disorders in the future. Therefore, further studies are needed at the molecular level to examine the mode of action of gabapentin in different brain tissues. In the years to come, continued investigations of the GABA system in the rodent, primate, and human brain, and the characterization of changes in specific phenotypic subclasses of interneurons in schizophrenia and bipolar disorder, will undoubtedly provide important new insights into how the integration of this transmitter system may be altered in neuropsychiatric disease. ${ }^{46}$

\section{Conclusion}

This study is probably the first open-label pilot research examining clinical outcomes of adjunctive treatment with gabapentin in partially responsive schizophrenia. Although clozapine is currently the recommended drug for resistant schizophrenia when other antipsychotics fail, it is associated with a number of limitations, some of which are serious. This makes the administration of clozapine a cumbersome process for both patients and clinicians. At this point in time, there is a great need for a drug or drug combinations to have a more effective clinical response with fewer serious side effects.

Gabapentin may have properties that enhance anti psychotic effects when added to antipsychotics in patients 
suffering from schizophrenia. However, the significance of the results from the current study needs to be interpreted cautiously because of its limitations, which include a small sample, an open study design, the absence of a clozapine treatment arm, and the lack of a systematic safety evaluation. Further controlled, double-blind studies are needed to examine the efficacy of gabapentin in the treatment of schizophrenia.

\section{Acknowledgment}

The author would like to thank Dr Thomas Raedler for reviewing the manuscript for this study.

\section{Disclosure}

This research project did not receive financial support from any source. It has been published in abstract form in the proceedings of the 21st Annual Meeting of the American Neuropsychiatric Association, held in Tampa, Florida, on March 19-21, 2010.

\section{References}

1. Taylor D, Duncan-McConnell D. Refractory schizophrenia and atypical antipsychotics. J Psychopharmacol. 2000;14:409-418.

2. Meltzer HY. Treatment-resistant schizophrenia - the role of clozapine. Curr Med Res Opin. 1997;14:1-20.

3. Swartz M, Stroup T, McEvoy J, et al. What CATIE found: Results from the schizophrenia trial. Psychiatr Serv. 2008;59:500-506.

4. Meltzer H, Alphs L, Green A, et al; International Suicide Prevention Trial Study Group. Clozapine treatment for suicidality in schizophrenia: International Suicide Prevention Trial (InterSePT). Arch Gen Psychiatry. 2003;60:82-91.

5. Tiihonen J, Lönnqvist J, Wahlbeck K, et al. 11-year follow-up of mortality in patients with schizophrenia: A population-based cohort study (FIN11study). Lancet. 2009;22:620-627.

6. Sernyak MJ, Desai R, Stolar M, Rosenheck R. Impact of clozapine on completed suicide. Am J Psychiatry. 2001;158:931-937.

7. de Hert M, Correll C, Cohen D. Do antipsychotic medications reduce or increase mortality in schizophrenia? A critical appraisal of the FIN-11study. Schizophr Res. 2010;117:68-74.

8. Atkinson JM, Douglas-Hall P, Fischetti C, Sparshatt A, Taylor DM. Outcome following clozapine discontinuation: A retrospective analysis. J Clin Psychiatry. 2007;68:1027-1030.

9. Dratcu L, Grandison A, McKay G, Bamidele A, Vasudevan V. Clozapine-resistant psychosis, smoking, and caffeine: Managing the neglected effects of substances that our patients consume every day. Am J Ther. 2007;14:314-318.

10. Alvir J, Lieberman J, Safferman A, Schwimmer J, Schaaf J. Clozapineinduced agranulocytosis. Incidence and risk factors in the United States. N Engl J Med. 1993;329:162-167.

11. Stahl S, Grady M. A critical review of atypical antipsychotic utilization: Comparing monotherapy with polypharmacy and augmentation. Curr Med Chem. 2004;11:313-327.

12. Wassef A, Dott S, Harris A, et al. Critical review of GABA-ergic drugs in the treatment of schizophrenia. J Clin Psychopharmacol. 1999;19: 222-232.

13. Tuominen HJ, Tiihonen J, Wahlbeck K. Glutamatergic drugs for schizophrenia. Cochrane Database Syst Rev. 2006;19:CD003730.

14. Tribut O, Bentué-Ferrer D, Verdier MC. Therapeutic drug monitoring of gabapentin. Therapie. 2010;65:57-60. French.

15. Landmark CJ. Targets for antiepileptic drugs in the synapse. Med Sci Monit. 2007;13:RA1-RA7.
16. Ng G, Bernard S, Sullivan R, et al. Gamma-aminobutyric acid Type B receptors with specific heterodimer composition and post synaptic action in the hippocampal neurons are targets of anticonvulsant gabapentin action. Mol Pharmacol. 2001;59:144-152.

17. Sills G. The mechanism of action of gabapentin and pregabalin. Curr Opin Phamacol. 2006;6:108-113.

18. Marais E, Klughauer N, Hofman F. Calcium channel alpha (2) delta subunit structure and gabapentin binding. Mol Pharmacol. 2001;59: $1243-1248$.

19. Handforth A, Treiman M. Efficacy and tolerance of long term, high dose gabapentin: Additional observations. Epilepsia. 1994;35: 1032-1037.

20. Goa K, Sorkin E. Gabapentin: A review of its pharmacological properties and clinical potential in epilepsy. Drugs. 1993;46:409-427.

21. Demily C, Franck N. Gabapentin for ultra resistant schizophrenia with aggressive behavior. Schizophr Res. 2008;100:349-350.

22. Megna JL, Devitt PJ, Sauro MD, Dewan MJ. Gabapentin's effect on agitation in severely and persistently mentally ill patients. Ann Pharmacother. 2002;36:12-16.

23. Cabras PL, Hardoy MJ, Hardoy MC, Carta MG. Clinical experience with gabapentin in patients with bipolar or schizoaffective disorder: Results of an open-label study. J Clin Psychiatry. 1999;60: 245-248.

24. Bennett J, Goldman WT, Suppes T. Gabapentin for treatment of bipolar and schizoaffective disorders. J Clin Psychopharmacol. 1997;17: $141-142$.

25. Pfeffer G, Chouinard G, Margolese HC. Gabapentin in the treatment of antipsychotic-induced akathisia in schizophrenia. Int Clin Psychopharmacol. 2005;20:179-181.

26. Hardoy M, Carta M, Carpiniello B, et al. Gabapentin in antipsychoticinduced tardive dyskinesia: Results of 1-year follow-up. JAffect Disord. 2003; $75: 125-130$

27. Usiskin S, Nicoloson R, Lenane M, Rapoport J. Gabapentin prophylaxis of clozapine induced seizures. Am J Psychiatry. 2000;157:482-483.

28. Sheehan DV, Lecrubier Y, Sheehan KH, et al. The Mini-International Neuropsychiatric Interview (M.I.N.I.): The development and validation of a structured diagnostic psychiatric interview for DSM-IV and ICD-10. J Clin Psychiatry. 1998;59 Suppl 20:22-33.

29. Kay SR, Fiszbein A, Opler LA. The positive and the negative syndrome scale (PANSS) for schizophrenia. Schizophr Bull. 1987;13:79-103.

30. Addington D, Addington J, Maticka-Tyndale E. Specificity of the Calgary Depression Scale for Schizophrenia. Schizophr Res. 1994;11: 239-244.

31. Chouinard G, Chouinard-Ross A, Annable L, Jones B. Extrapyramidal rating scale. Can J Neurol Sci. 1980:7;233.

32. Leucht S, David J, Engel R, Kissling W, Kane J. Definition of response and remission in schizophrenia: Recommendation for their use and their presentation. Acta Psychiatr Scand. 2009;119:7-14.

33. Rogawski M. Astrocytes get in the act in epilepsy. Nat Med. 2005;11: 919-920.

34. Benes FM. The role of stress and dopamine-GABA interactions in the vulnerability for schizophrenia. J Psychiatr Res. 1997;31:257-275.

35. Tamminga CA, Crayton JC, Chase TN. Muscimol: GABA agonist therapy in schizophrenia. Am J Psychiatry. 1978;135:746-748.

36. Koran L. Gamma aminobutyric acid deficiency in schizophrenia. Lancet. 1976;2:1025.

37. Bowden CL. New concepts in mood stabilization: Evidence for the effectiveness of valproate and lamotrigine. Neuropsychopharmacology. 1998;19:194-199.

38. Johannessen C. Antiepileptic drugs in non-epilepsy disorders: Relations between mechanisms of action and clinical efficacy. CNS Drugs. 2008; 22:27-47.

39. Rogawski MA, Löscher W. The neurobiology of antiepileptic drugs for the treatment of nonepileptic conditions. Nat Med. 2004;10: 685-692.

40. Yatham LN, Kennedy SH, O'Donovan C, et al; Guidelines Group, CANMAT. Canadian Network for Mood and Anxiety Treatments (CANMAT) guidelines for the management of patients with bipolar disorder. Bipolar Disord. 2006;8:721-739. 
41. Hosák L, Libiger J. Antiepileptic drugs in schizophrenia: A review. Eur Psychiatry. 2002;17:371-378.

42. Barnes TRE, McEvedy CJB, Nelson HE. Management of treatmentresistant schizophrenia unresponsive to clozapine. Br J Psychiatry. 1996;169 Suppl 31:31-40.

43. Tiihonen J, Wahlbeck K, Kiviniemi V. The efficacy of lamotrigine in clozapine-resistant schizophrenia: A systematic review and meta-analysis. Schizophr Res. 2009;109:10-14.
44. Large CH, Webster EL, Goff DC. The potential role of lamotrigine in schizophrenia. Psychopharmacology. 2005;181:415-436.

45. Goff DC, Keefe R, Citrome L, et al. Lamotrigine as add-on therapy in schizophrenia: Results of 2 placebo-controlled trials. J Clin Psychopharmacol. 2007;27:582-589.

46. Benes F, Berretta S. GABAergic interneurons: Implications for understanding schizophrenia and bipolar disorder. Neuropsychopharmacology. 2001;25:1-27.

\section{Publish your work in this journal}

Neuropsychiatric Disease and Treatment is an international, peerreviewed journal of clinical therapeutics and pharmacology focusing on concise rapid reporting of clinical or pre-clinical studies on a range of neuropsychiatric and neurological disorders. This journal is indexed on PubMed Central, the 'PsycINFO' database and CAS, and is the official

Submit your manuscript here: http://www.dovepress.com/neuropsychiatric-disease-and-treatment-journal journal of The International Neuropsychiatric Association (INA). The manuscript management system is completely online and includes a very quick and fair peer-review system, which is all easy to use. Visit http://www.dovepress.com/testimonials.php to read real quotes from published authors. 